\title{
Research on Land Use Change and Ecological Environment Effect Based on Remote Sensing Sensor Technology
}

\author{
Yuntong Liu $\mathbb{D},{ }^{1,2,3}$ Dan Zhang $\mathbb{D}^{2},{ }^{2}$ Kuan He $\mathbb{D}^{2},{ }^{2}$ Qiong Gao $\mathbb{D}^{2}$, and Fen Qin $\mathbb{D}^{1,3}$ \\ ${ }^{1}$ The College of Geography and Environment, Henan University, Kaifeng Henan 475004, China \\ ${ }^{2}$ Yellow River Conservancy Technical Institute, Kaifeng Henan 475004, China \\ ${ }^{3}$ Henan Industrial Technology Academy of Spatio-Temporal Big Data, Zhengzhou Henan 450046, China
}

Correspondence should be addressed to Fen Qin; qinfen@henu.edu.cn

Received 13 August 2021; Accepted 28 August 2021; Published 17 September 2021

Academic Editor: Guolong Shi

Copyright (c) 2021 Yuntong Liu et al. This is an open access article distributed under the Creative Commons Attribution License, which permits unrestricted use, distribution, and reproduction in any medium, provided the original work is properly cited.

In the regional landscape pattern, woodland landscape patches are developed in a regular manner, showing a trend of agglomeration as a whole; the concentration and dominance of landscape patches of cultivated land, grassland, and unused land are decreasing, and the overall situation is fragmented; the water landscape pattern is also showing a regular development state to varying degrees. On the whole, the landscape of a certain area is scattered and fragmented, and the dominant landscape types dominate the overall landscape layout of the region. The diversity of land use landscape pattern shows positive autocorrelation as a whole. According to the Moran's $I$ index of the diversity of land use landscape patterns, the overall agglomeration effect of the region has increased, but the overall trend is in a balanced trend. The ecological service value of urban land use change continues to increase, but the regional differences are significant, the structure is simple, and it is mainly supported by ecosystems such as forest land, water area, and agricultural land. Based on the analysis of the spatiotemporal evolution of land use, an in-depth analysis of the urban water environment, atmospheric environment, soil environment, urban heat island, and other environmental issues of the urban land use in the study area is carried out. The calculation and analysis results of the ecological service value of urban land use change and its flow direction change show that the ecosystem service value has increased, and the regional difference and flow direction of the ecosystem service value have changed significantly.

\section{Introduction}

Remote sensing technology is a detection technology based on aerial photography technology. This technology detects and perceives objects and things from a distance. It uses sensing instruments to collect and process electromagnetic wave information from distant targets $[1,2]$. At present, it has been widely used in military reconnaissance, military surveying and mapping, meteorological observation, missile early warning, and other fields [3]. It is also used in earth resources. Census, land use planning, crop yields, and other civilian aspects have been widely used. It has the characteristics of a wide range of information acquisition, convenient, accurate and rapid acquisition of information, limited data acquisition, and multiple information acquisition methods. It is in a leading position in large-scale land resource moni- toring. In recent years, remote sensing technology has gradually transformed from qualitative to a fusion of qualitative and quantitative [4]. Geography has entered a new stage of development [5].

The land resources that can be utilized have become increasingly tense. Therefore, it is very important to monitor land use information. Due to the limitations of the technology at that time, the investigation time was too long and the error of the obtained results was too large. After entering the twentieth century, the population has grown rapidly and the available resources of land have become less and less, which has caused countries around the world to pay more and more attention to the status of land use [6,7]. The number of people concentrated in cities and the area covered by cities are expanding day by day. If you do not pay attention, serious problems of pollution and damage to the environment and 
ecological balance will occur, which will become more prominent in land use. As an important research content of humanities and economy, land use plays a pivotal role in the treatment of the relationship between man and land and the development of the national economy [8]. The timeliness and comprehensiveness of remote sensing technology make it a reality to monitor land use quickly and accurately. Because of the comprehensiveness of remote sensing information, the complexity of remote sensing imaging principles, and the backwardness of information processing technology relative to information acquisition technology, high-precision automatic and intelligent land use monitoring has not yet been realized, and the accuracy of automatic interpretation is often lower than that of visual interpretation [9].

This study is performed to analyze and study the land use pattern and time-space dynamics in a certain area, establish an index system for the driving mechanism, and evaluate the ecological environment effect of the area. And the construction of a harmonious ecological environment in the area provides a basis for decision-making. Through the processing of band fusion, image correction, and image enhancement of TM images in various periods, images with high definition and obvious spatial characteristics are obtained. According to the spectral characteristics of ground objects, a layered extraction method is designed to extract land use information. By selecting a variety of landscape pattern indexes, we analyze the overall landscape level and landscape type level of the study area and quantitatively analyze the temporal and spatial evolution characteristics of various land use types in a certain area and land types in different years. The spatial autocorrelation analysis is carried out by selecting the appropriate landscape pattern index. Global autocorrelation is mainly a reflection of the overall landscape characteristics of a certain area; local autocorrelation focuses on the autocorrelation of each township and studies the changes in land use types and quantities from a small scale. The ecological service value of urban land use change continues to increase, but the regional differences are significant, the structure is simple, and it is mainly supported by ecosystems such as forest land, water area, and agricultural land.

\section{Related Work}

Relevant scholars fuse panchromatic SPOT data with multispectral TM information and merge the information fusion technology with time information to form a new method of variation feature monitoring to monitor land use changes $[10,11]$. Certain data constraints have greatly improved the accuracy of monitoring, which is conducive to the study of land use changes. Through classification, the monitoring method can be divided into variable vector method, direct principal component method, direct interpolation method, classification comparison method, etc. The disadvantage is that it is only monitored for a single land use type. At present, the research direction of new monitoring technologies in the future has become the focus of attention of scholars [12].
Land is a natural complex, mainly composed of soil, organisms, rocks, and atmosphere. At the same time, humans make certain changes to the land, resulting in varying degrees of influence on the elements of the land. The spatial scale of the research is different, and the research period is also different, and the factors that change the land use must be different. In the early stage of the research, due to the low level of economy and technology, the time scale was relatively long, and the natural attributes of the land itself mainly restricted the change of land use. Therefore, natural factors were the main driving factors of land use. When the level of economy and technology is relatively high and the time scale is relatively short, human activities become the main driving factor of land use change. The discussion on the driving factors and driving mechanisms of land use/cover change is the prerequisite and basis for the future development of the study of regional land use change. At present, foreign scholars are mainly analyzing and comparing cases to study the driving mechanism of land use/cover change, in different regions and different research scales, modeling land use changes to analyze the time of land use/cover change and the characteristic law of evolution. At present, the latest international research perspective on land use/cover change research is to select relevant mathematical models and analyze their driving forces.

In the research process, foreign scholars in China are mainly based on the theory of man-land relationship and believe that man-land relationship is the entry point for studying land use/cover change [13]. Subsequently, the research continued to deepen and refine, and the study of land cover was in-depth in time and space to explore the process of land use change $[14,15]$. The application of landscape ecology provides theoretical support and research methods. The resulting remote sensing technology not only expands the research scale but also changes the research period from the past to the future. It adds technical means to obtain land use changes, adds data sources for the study of land use changes, and can explore the evolution of land use in time and space. Subsequently, the theoretical support of digital image processing, spectroscopy theory, and imaging theory provided theoretical support for obtaining land use change information. At present, scholars have explored the system of land use classification in remote sensing data, which has laid the foundation for remote sensing dynamic monitoring [16, 17]. They use remote sensing technology and human-computer interaction methods to interpret the images needed for research; perform preprocessing, analysis, and pattern recognition of remote sensing images; and apply a fast, efficient, and low-cost management model [18, 19].

The ecological and environmental effects of land use have gradually become one of the focuses of the academic community. Through the analysis of land use changes, relevant scholars revealed that local ecosystems are severely affected by land use and then analyzed the imbalance of greenhouse gases on a global scale $[20,21]$. The research found that in the tropics, changes in land use and human activities in the process of agricultural raw tea have a certain impact on human $\mathrm{N}_{2} \mathrm{O}$ in the atmosphere, causing its content to increase. The study found that the area change of 


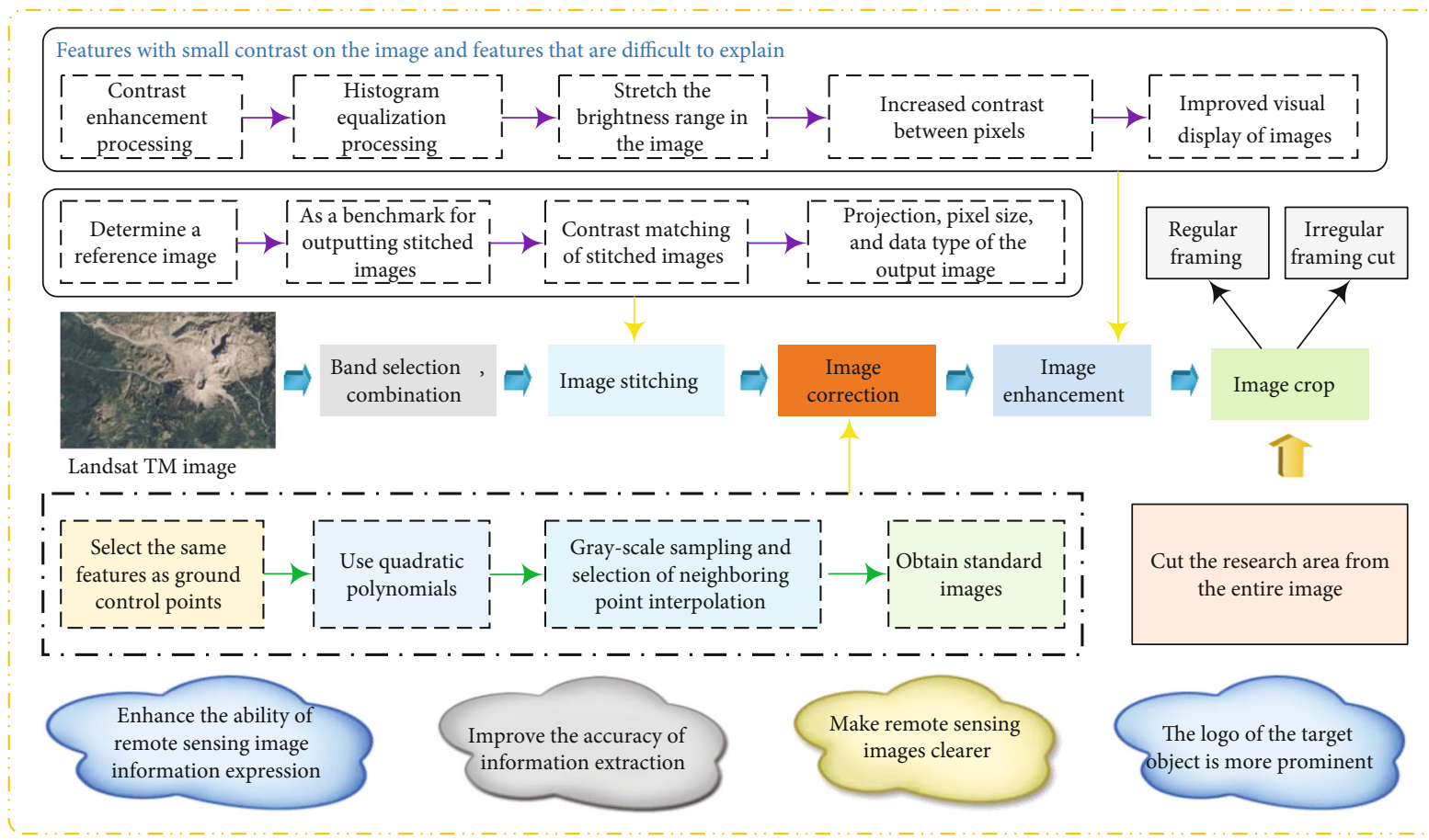

FIGURE 1: Schematic diagram of remote sensing image preprocessing.

the Amazon forest seriously affects the local precipitation. In the study of soil effects, it is mainly to analyze and discuss the nature of soil physics and chemistry, soil erosion, and soil degradation [22]. The research in this area mainly includes two aspects: one is the process, mechanism, influencing factors, and monitoring and early warning system of soil degradation; the other is the construction of an evaluation index system for soil and soil degradation. The impact on water resources is mainly included in water quantity and water quality. In the process of land use, construction land continues to expand, especially in agricultural production; a large number of agricultural fertilizers, pesticides, etc. are used, causing some chemical substances and particulate matter to flow into the groundwater layer and rivers, causing different degrees of pollution in water bodies [23-25].

The process of discussing biological effects includes two aspects: one is the change in land use, which leads to changes in biodiversity; the other is the change in land use, which also changes the ecosystem service functions. The cause of the change in biodiversity is the change in land use, and the factors of land use and global change affect and change biodiversity. Studies have shown that in the process of extending the agricultural reclamation area to the forest area, the ecological environment of the fringe area is affected or even destroyed, which changes the climate in the study area and at the same time is invaded by foreign organisms. Biodiversity is severely reduced. Land use/cover change is the closest link between humans and natural resources. It not only changes the basic functions of material circulation and energy flow in the ecosystem but also has a certain impact on the value of ecosystem services.

\section{Data Processing and Information Extraction Methods Based on Remote Sensing Sensor Technology}

3.1. Data Processing. The remote sensing image characterizes the spatial distribution of the spectral radiant energy of the ground object. The intensity of the radiant energy is related to certain characteristics of the ground object. The schematic diagram of remote sensing image preprocessing is shown in Figure 1.

Remote sensing subbands record the subtle differences in the spectra of ground objects and make full use of the differences in ground objects at different wavebands to identify objects more effectively. However, there is often a greater correlation between multiband data, and this kind of data redundancy must be considered in multiband data fusion. For Landsat TM images, there are 7 bands, and for every 3-band combination, there can be many synthesis schemes. Different application purposes and different research objects require different combination schemes. This research is performed to monitor the dynamic process of land use/land cover change in the study area and extract land type change information. In order to enable remote sensing images to provide more categories and higher classification accuracy and to highlight the characteristics of land use types, the three-band composite image is required to have a large amount of information, low correlation, low redundancy, and obvious characteristics of desertification. Therefore, statistical analysis and correlation analysis are carried out on the 7-band information characteristics of the TM in the study area. In the ERDAS 8.7 software, you use the combined multiband data function to combine single-band 


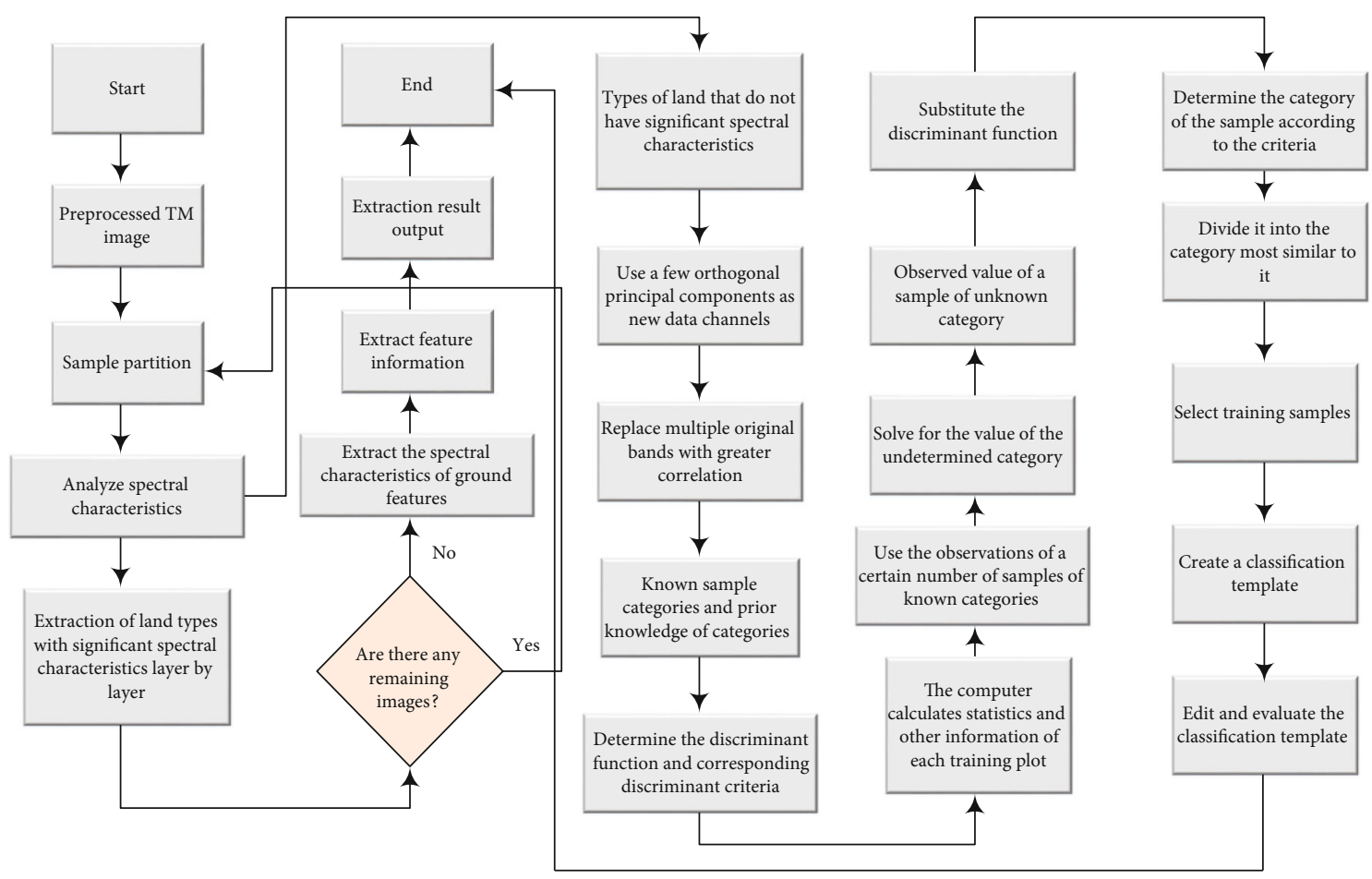

FIGURE 2: Remote sensing information extraction process of land use change.

IMG files into a multiband image file with obvious land use/land cover information characteristics.

3.2. Information Extraction Method. The extraction of land use information uses a combination of hierarchical classification and principal component analysis and supervised classification. Figure 2 is a flowchart of a method for extracting land use change information based on remote sensing sensor technology. We first determine the regional samples of different land use types on the preprocessed images, analyze the spectral information of the samples, design a hierarchical classification scheme obtained by statistical analysis of the samples, and extract the information layer by layer. In the process of layered extraction, we first extract the types of features with significant spectral features. Considering that some features do not have significant spectral features on the original image, the principal component analysis (PCA) method is used to perform principal component analysis. We transform, synthesize, and enhance the spectral information of the ground features and extract the spectral features of the ground features. Then, the extracted information is removed from the principal component transformed image using a mask method, and the remaining unsegmented images are supervised and classified by the supervised classification method to extract feature information.

Hierarchical classification is mainly based on the laws of geoscience differentiation in remote sensing images, and for images belonging to different categories or landscape areas, through hierarchical division, different classification decision rules are used to gradually classify from coarse to fine. This method fully considers the characteristic attributes of various ground objects; adopts a step-by-step logical discrimination method; enhances the information extraction ability, classification accuracy, and calculation efficiency; and shows greater flexibility in data analysis and interpretation methods. The principle is to analyze the separability of the feature types in each band and combination and first divide the features on the image into several first-level layers and then further decompose it into different secondary and tertiary layers. According to the spectral characteristics of the objects to be classified, different feature parameters and classification methods are selected, the information is extracted layer by layer and the corresponding template is made, and the extracted information is masked from the image to eliminate its extraction of other types of objects. As a result, there are fewer and fewer remaining types on the image, and the classification of the next layer of features becomes easier and easier. Finally, the result of the layer-bylayer classification is superimposed into the final classification result. Taking into account the characteristics of the accumulation of stratified classification errors, classification should be made from low to high (from easy to difficult) according to the size of the separation error of the land use category in the strata.

\subsection{Hierarchical Classification and Land Use Classification} Technology System under PCA Supervision and Classification. The land use classification technology system based on hierarchical classification and PCA supervised classification first separates water bodies from other types and secondly divides nonwater bodies into vegetation areas and nonvegetation areas according to the normalized vegetation index (NDVI). Combined with PCA supervised classification, the land type information is extracted layer by layer. Some of the desertified land has low-coverage vegetation growth. Considering that the NDVI's ability to detect low-coverage vegetation in 


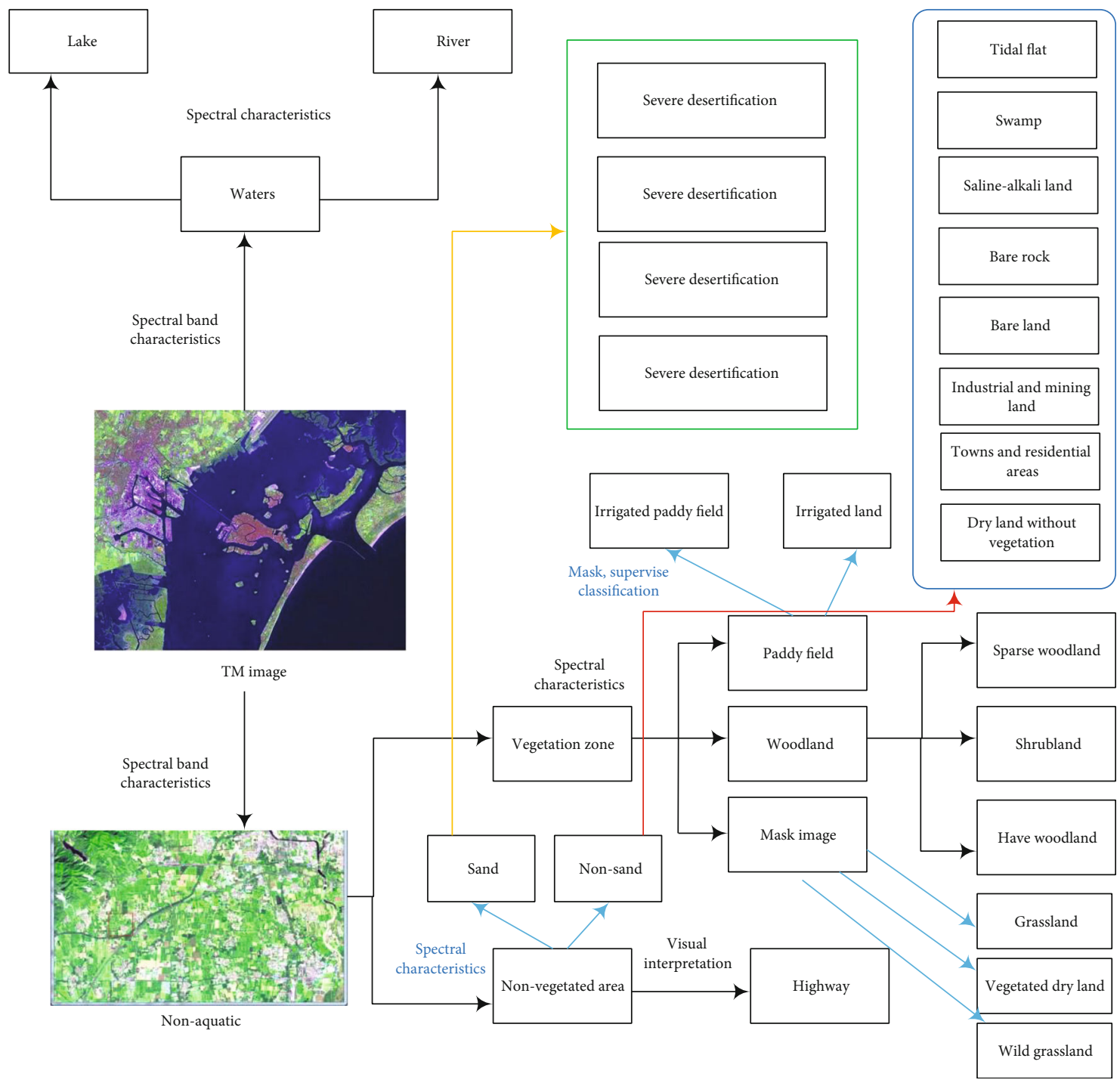

Figure 3: Decision tree structure of land use classification technology system.

semiarid areas is reduced, in fact, the study area is arid and rainless, and the growth of sand vegetation is withered and sparse. The electromagnetic reflection is mainly the reflection of its background. Therefore, the vegetation area distinguished by NDVI does not include sand vegetation. In the experiment, it was found that although the spectral features of some ground objects are prominent, they are easily mixed with other types in some bands. Therefore, the threshold value was set in conjunction with the threshold method when extracting. In the extraction, the types of land are simple, but the types of ground objects with insignificant spectral characteristics are also extracted by visual interpretation. The specific classification technology system is shown in Figure 3.

\section{Analysis of the Temporal and Spatial Evolution in a Certain Area}

4.1. Analysis of Characteristics of Land Use Quantitative Changes. The land types are diverse, mainly composed of the proportions of the various land types that make up the overall land resources. They are usually described by the extent and rate of land use change. It is selected to reflect the area change of each land type in the region during the study period. The formula is as follows:

$$
\delta=\frac{\left|C_{\mathrm{a}}-C_{\mathrm{b}}\right|}{C_{\mathrm{a}}} .
$$

In the formula, $\delta$ is the change range of a certain land use type during the study period; $C_{\mathrm{a}}$ and $C_{\mathrm{b}}$ represent the area at the beginning and end of the study, respectively.

4.1.1. Dynamic Degree of Single Land Use. Mainly, it refers to the average annual change of various land use types in a certain research period in the studied area, namely,

$$
K=\frac{\delta}{T} .
$$


TABLE 1: Main indicators of land use change in a certain area.

\begin{tabular}{|c|c|}
\hline Indicator code & Specific indicators \\
\hline 1 & Total output value of agriculture \\
\hline 2 & Total grain output (tons) \\
\hline 3 & $\begin{array}{l}\text { Real estate development investment } \\
\text { (ten thousand yuan) }\end{array}$ \\
\hline 4 & $\begin{array}{l}\text { Total output value of construction industry } \\
\text { (ten thousand yuan) }\end{array}$ \\
\hline 5 & $\begin{array}{l}\text { Total power of agricultural machinery } \\
\qquad(10,000 \text { watts })\end{array}$ \\
\hline 6 & Population density (person $/ \mathrm{km}^{2}$ ) \\
\hline 7 & $\begin{array}{l}\text { Output value of tertiary industry } \\
\text { (ten thousand yuan) }\end{array}$ \\
\hline 8 & Nonagricultural population (10,000 people) \\
\hline 9 & $\begin{array}{l}\text { Investment in fixed assets of the whole society } \\
\text { (ten thousand yuan) }\end{array}$ \\
\hline 10 & Gross domestic product (ten thousand yuan) \\
\hline 11 & Total population (10,000 people) \\
\hline 12 & $\begin{array}{l}\text { Primary industry output value } \\
\text { (ten thousand yuan) }\end{array}$ \\
\hline 13 & $\begin{array}{l}\text { Total retail sales of consumer goods } \\
\text { (ten thousand yuan) }\end{array}$ \\
\hline 14 & $\begin{array}{l}\text { Output value of the secondary industry } \\
\text { (ten thousand yuan) }\end{array}$ \\
\hline
\end{tabular}

In the formula, $K$ represents the land use dynamics of a certain land use type in the study area; $T$ is the length of the study period.

4.1.2. Comprehensive Land Use Dynamics. It mainly reflects the comprehensive trend of regional land use types and the regional difference indicators of land use changes during the study period. The expression is

$$
K_{\mathrm{c}}=\frac{\prod_{i=1}^{n}\left|\Delta C_{i-j}\right|}{\delta T \cdot \prod_{i=1}^{n} C_{i}} \cdot 100 \% .
$$

Among them, $K_{\mathrm{c}}$ represents the comprehensive utilization of regional land; $C_{i}$ represents the utilization area of the $i$ th type.

4.2. Analysis of Driving Forces of Land Use Change. It is necessary for us to establish a more comprehensive and scientific index system suitable for the regional characteristics of a certain area. The principal component analysis method simplifies multiple variables into several uncorrelated comprehensive variables for statistics, which can reduce the interference between independent variables and simplify research questions at the same time. Table 1 shows the main indicators of land use change in a certain area.

4.3. Evaluation of Land Use Landscape Pattern Index. According to the difference of different landform types, the indicators of the patch type level and the overall level of the patch are used for discussion. The patch type level is the basis for the calculation of other horizontal landscape indexes, but it cannot directly reflect the overall landscape of the area. The 6 selected indices are as follows:

(1) NP (number of patches), which reflects the human disturbance of the landscape

$$
\mathrm{NP}=\delta \bullet n_{i j}
$$

$n_{i j}$ represents the number of landscape patch types.

(2) PD (patch density) means the number of patches included in a unit area. The higher its density, it means that there are more patches in a certain area, the patch area is small, and the fragmentation of the landscape is more serious

$$
\mathrm{PD}=\frac{K_{\mathrm{c}} \cdot N_{\mathrm{c}}}{A_{\mathrm{c}}}
$$

$N_{\mathrm{c}}$ is the total number of landscape patches, and $A_{\mathrm{c}}$ is the entire area of the landscape.

(3) PAFRAC (patch fractal dimension), which reflects the complexity of the patch, and the value range is

$$
\text { PAFRAC }=\frac{2\left|C_{\mathrm{a}}-C_{\mathrm{b}}\right| \cdot \log (1 / p)}{\log A_{\mathrm{c}}}
$$

$P$ is the circumference of the plaque.

(4) AI (degree of aggregation), which mainly reflects the degree plaque types. The larger the AI, the higher the compactness of the plaque and the lower the degree of fragmentation:

$$
\mathrm{AI}=\delta T \cdot \frac{g_{i j}}{\operatorname{Max}} \cdot 100 \%
$$

$g_{i j}$ is the number of similar adjacencies of type $i$, and Max is the number of adjacencies with the greatest degree of similarity.

(5) PLAND (patch area ratio), which is the percentage of a certain patch type to the area of the entire landscape patch; the value range is between 0 and 100:

$$
\text { PLAND }=\frac{\prod_{j}^{n} a_{i j}}{\delta A_{c}}
$$

This indicates the proportion of patch types in the landscape.

(6) IJI (Dispersion and Juxtaposition Index) is one of the important indicators to describe the spatial structure of the landscape. Its size reflects the number of other 
types that are critical to the patch type. The smaller the value, the fewer the other adjacent patch types:

$$
\mathrm{IJI}=\prod_{j=0}^{m-1} \frac{\ln D_{i j} \cdot \sum_{j=0}^{m-1} D_{i j}}{\ln (m-1)} \cdot 100 \%
$$

$D_{i j}$ is the length of the connecting plaques of plaque types $i$ and $j$.

4.4. Spatial Autocorrelation Analysis. As one of the important methods in exploratory spatial data analysis and research, spatial autocorrelation is mainly divided into global autocorrelation and local autocorrelation. It means that the objects with similar characteristics are relatively close. On the contrary, if the spatial autocorrelation is weak or there is no autocorrelation, it means that the distributed objects are not correlated.

It can fully reflect the spatial autocorrelation of the land use structure, with a value range of $-1 \sim+1$. If it is greater than zero, there is a positive correlation, otherwise, it is negative, and if it is equal to zero, there is no correlation. It is calculated as follows:

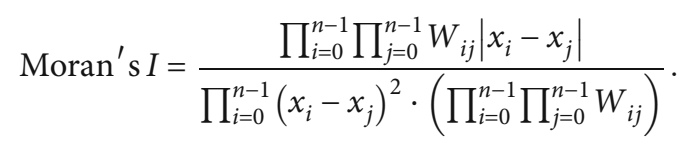

In the formula, $x_{i}$ is the value of land use diversity in area $i, x_{j}$ is the value of land use diversity in area $j, W_{i j}$ is the spatial weight, and contiguity is selected as the spatial weight matrix in the text.

Global autocorrelation only analyzes the attributes of the study area from the overall perspective and cannot describe the specific distribution of the area. Therefore, it is necessary to use local autocorrelation to analyze the regional characteristics. The paper mainly uses the LISA model to study the properties of the local spatial autocorrelation of the study area. The formula is as follows:

$$
\text { Moran's } I=Z_{i} \cdot \prod_{i=0}^{n-1} \prod_{j=0}^{n-1}\left(W_{i j} Z_{j}\right)
$$

In the formula, $Z_{i}$ and $Z_{j}$ represent the standardized scores of the land use diversity value of township $i$ and township $j$, respectively.

\section{Numerical Analysis of the Ecological Environmental Effects}

5.1. Analysis of Ecological Service Value Flow. The profit and loss of the ecological service value caused by the mutual conversion is

$$
\mathrm{PL}_{i j}=\delta \cdot A_{i j} \cdot\left|\mathrm{VC}_{i}-\mathrm{VC}_{j}\right|
$$

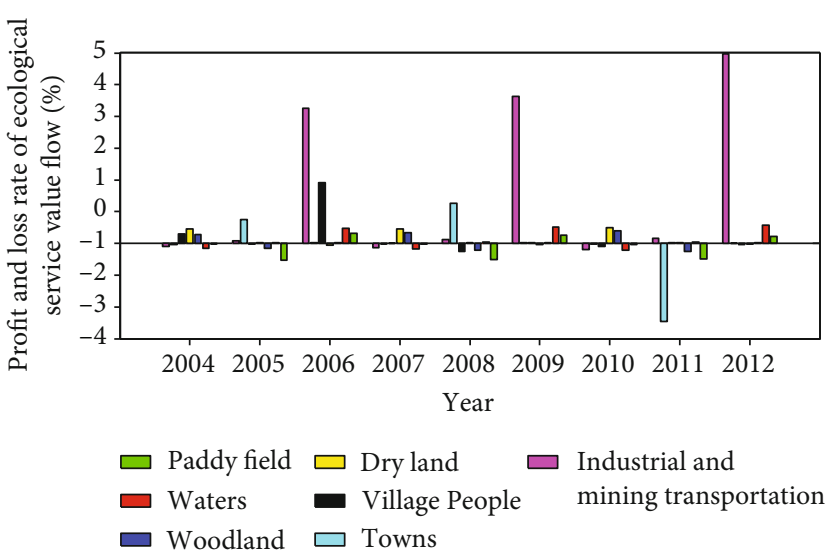

FIgURE 4: The profit and loss rate of the ecological service value flow of land use change from 2004 to 2012.

where $\mathrm{PL}_{i j}$ is the ecological service value gains and losses after the initial $i$ th landscape is transformed into the $j$ th landscape at the end; $\mathrm{VC}_{i}$ and $\mathrm{VC}_{j}$ are the ecological service value coefficients of the $i$ th landscape and the $j$ th landscape, respectively; and $A_{i j}$ is the $i$ th landscape converted to the area of the $j$ th landscape.

The increase or decrease in the value of ecological services caused by the conversion of landscape types is regarded as flowing, the increase of ecological service value is a positive flow direction, and the decrease of ecological service value is a negative flow direction.

5.1.1. Analysis from 2004 to 2012. Converting forest land and water areas into cultivated land and construction land will reduce the value of ecological services, while converting cultivated land and construction land into forest land and water areas will increase the value of ecological services. The value of forest areas mainly flows to waters, landfills, dry land, and construction land. The ecological service value of the forest area flowing through the water area is greater, and the forest flowing through the mature farmland is drier. Land construction belongs to negative circulation, which is not conducive to the circulation of ecological service value. The ecological value of water mainly flows to forests, mature farmland, dry land, and construction land. The value of water ecological services flowing nearby is greater. Fields, dry land, and construction land have the highest negative trend value. The ecological service value of forest land is high, and the water area and its negative direction continue to develop. Suit field flow is construction land. The ecological value of dry land mainly comes from forest land, water area, and construction land. Among them, the ecological service value of forest land is higher, followed by water area. The negative direction of the suit field flow is construction land. The ecological value of construction land mainly comes from the positive flow of forests, water areas, and dry land. It can be seen from Figure 4. From 2004 to 2012, the value of ecological services caused by changes in land use showed a strong trend. 


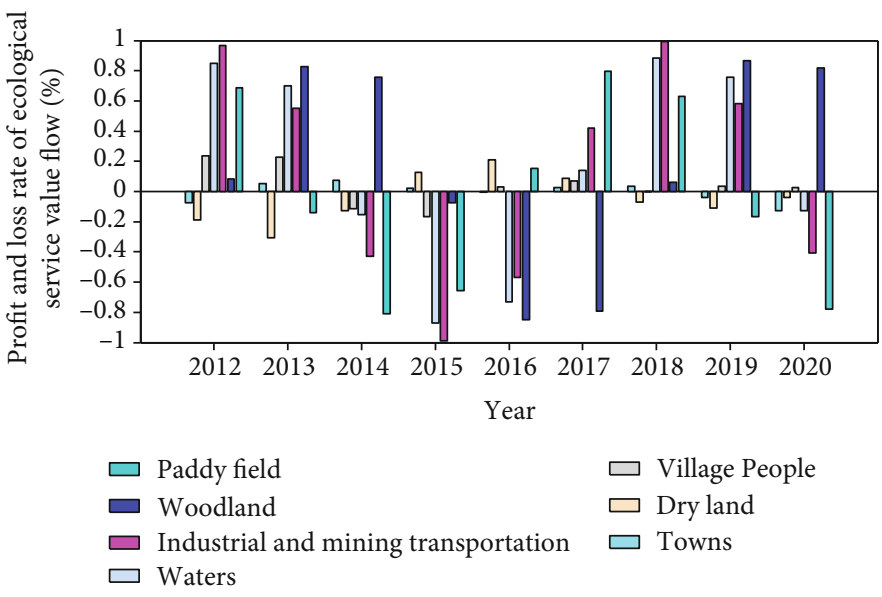

FIgURE 5: The profit and loss rate of the ecological service value flow of land use change from 2012 to 2020.



Figure 6: The profit and loss rate of the ecological service value flow of land use change from 2004 to 2020.

5.1.2. Analysis from 2012 to 2020. Compared with the changes in the value of ecological services caused by changes in land use from 2012 to 2020, the total value of ecological services has shown a downward trend. The larger the area that enters other lands, the greater the value of the ecosystem. The conversion of cultivated land and construction land will have a negative impact on the overall value of ecological services; the service value is positive. Figure 5 shows the impact of changes in benefits and land use loss levels on the value of ecological service flows from 2012 to 2020.

5.1.3. Analysis from 2004 to 2020. The value of ecosystem services from rural residential areas to other land uses is flowing to the largest forest land, and the value of ecosystem services from the conversion of forest land and water to the largest forest land leads to the positive value stream of ecosystem services and benefits from the total value of ecosystem services. On the other hand, the conversion of cultivated land and construction land leads to the negative value of ecosystem services, which does not support the overall value of ecosystem services. The value of other types of land use ecosystem services is positive, but the value of other types of land use ecosystem services is negative. It is negative and does not support the value flow across ecosystem services. The flow of ecosystem service value created by the conversion of construction land into other land is positive. Figure 6 shows the profit/loss ratio of the land use change ecosystem from 2004 to 2020.

\subsection{Analysis of Regional Differences in Ecological Service} Value Flows

5.2.1. Analysis of the Flow Direction in Region 1. Changes in the value of ecosystem services caused by changes in regional land use from 2004 to 2020 are not conducive to the overall development of ecosystem services. The ecosystem services produced by the conversion of cultivated land and construction land are positive. Industrial land and mining land will be converted into other land and ecosystem services. The value + trend increase, and the negative trend of ecosystem service value increases. When forest land changes, the conversion of forest land and water area is the connection of the positive value of ecosystem services. This is the full value of ecosystem services to bring benefits, but the conversion of cultivated land and construction land to services results in 


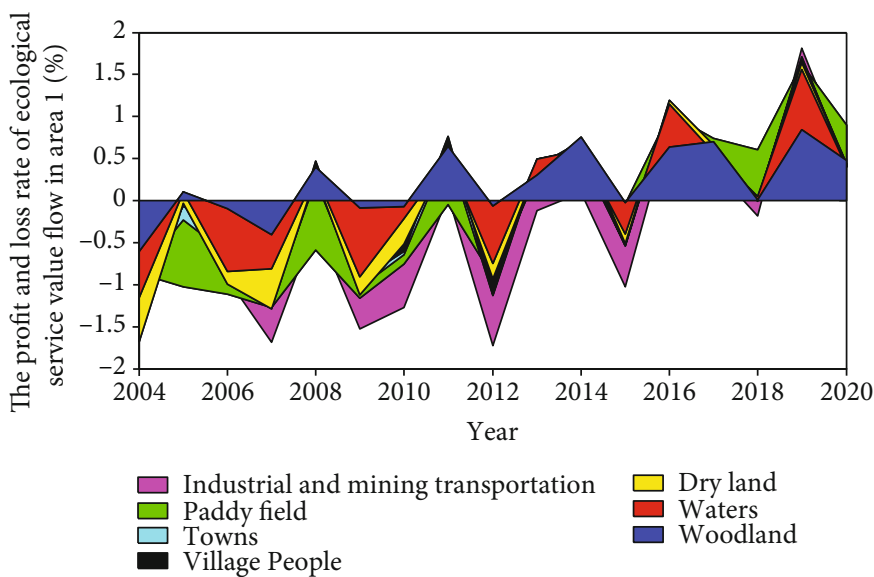

FIgURE 7: The profit and loss rate of the ecological service value flow of land use change in Region 1 from 2004 to 2020.

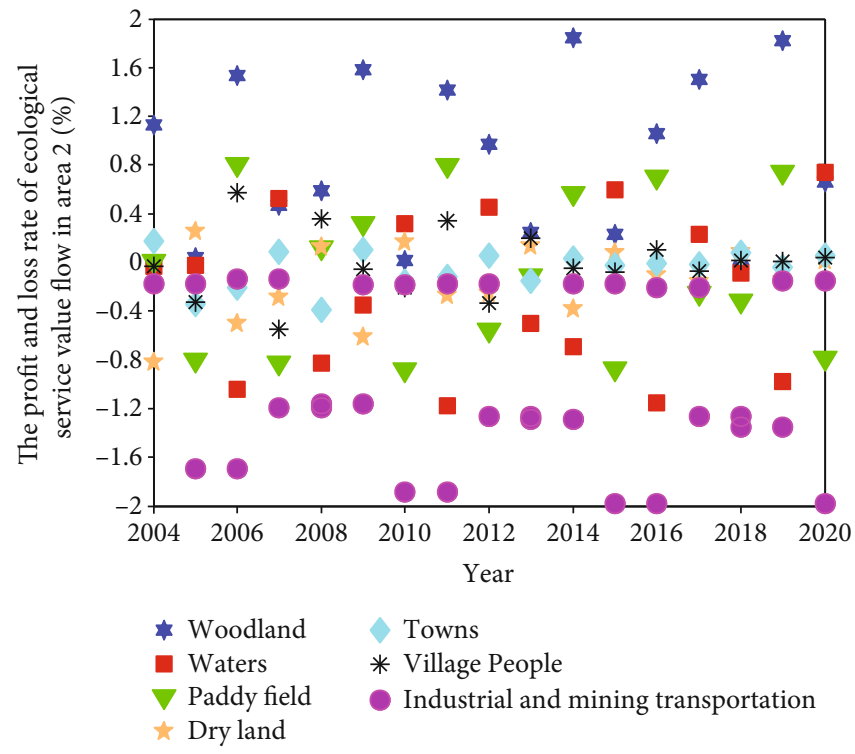

FIgURE 8: The profit and loss rate of the ecological service value flow of land use change in Region 2 from 2004 to 2020.

the overall negative value of ecosystem services. The value ecosystem does not support services; the ecological service value of other types of land use is positive, but the ecological service value of other types of land use is negative for construction land (cities, industries, mines, and rural villages), and the trend is connected. This is negative growth. I do not support the trend of overall ecosystem service value. Ecosystem services produced by conversion from construction land to other land are a plus. Figure 7 shows the relationship between the benefits and losses of ecosystem service value streams and land use changes in a region from 2004 to 2020.

5.2.2. Analysis on the Flow of Ecological Service Value of Land Use Change in Region 2. By converting rural houses to other land use patterns, the positive flow of ecological service value is maximized, and the conversion of forests to other land use patterns will result in a negative flow of ecological service value. In the largest case, the conversion of forests and water will create positive value for ecosystem ser- vices, which will have a positive impact on the overall value of ecosystem services. There are negative values brought about by the conversion of cultivated land and construction land into ecosystem services. The value of ecosystem services generated by the migration of forests is the value of the entire ecosystem services. Is the positive trend of value fueled? This is the starting point of the ecosystem service value of the total construction land of the profession. Figure 8 shows the relationship between the gains and losses of land use changes to the value stream of ecosystem services in the standard area 2 for evaluating green buildings.

\section{Conclusion}

Based on the spectral characteristics of the ground features, combined with the threshold method, using the method of combining PCA and supervised classification, a multilevel hierarchical comprehensive classification method is established. This method makes use of the spectral characteristics of the ground features. According to the layered processing 
method from coarse to fine, easy first, and then difficult, the ground features on the image are first divided into several first-level layers and then further decomposed into secondlevel and third-level layers. Different feature parameters and classification methods are selected, information is extracted layer by layer, and corresponding templates are made. For the spectral features of the remaining unclassified images after principal component transformation, the supervised classification method is used to extract the more difficult to distinguish features. This method realizes the automatic classification of land use/cover types. The analysis of landscape pattern is to analyze the spatial change of landscape pattern in a region from two levels of patch type level and overall patch level by selecting landscape indicators. The patch density of cultivated land, woodland, grassland, water area, and unused land is increasing; the patch area is gradually getting smaller; and the whole landscape is showing a fragmented development trend. The patch density of construction land is decreasing, the patch area is gradually increasing, and its dominance is also increasing, and the patch shape tends to be regular. On the whole, the landscape in a certain area is fragmented and decentralized; the diversity of the spatial autocorrelation of the regional landscape pattern is also declining. Among them, arable land, grassland, and construction land play a major role in the overall landscape. The ecological service value of urban land use changes continues to increase, but the supporting ecosystem service value system is relatively simple.

\section{Data Availability}

The data used to support the findings of this study are available from the corresponding author upon request.

\section{Conflicts of Interest}

We declare that there is no conflict of interest.

\section{Acknowledgments}

This work was supported by the National Science and Technology Infrastructure Program Platform Aid Financially Project (No. 2005DKA32300), the project of Science and Technology Project of Henan Province (152102110047), the project of Major Science and Technology Project of Henan Province (121100111300), and National Earth System Science Data Sharing Infrastructure, National Science \& Technology Infrastructure of China-Data Center of Lower Yellow River Regions (http://henu.geodata.cn).

\section{References}

[1] X. Du and Z. Huang, "Ecological and environmental effects of land use change in rapid urbanization: the case of Hangzhou, China," Ecological Indicators, vol. 81, pp. 243-251, 2017.

[2] H. Dadashpoor, P. Azizi, and M. Moghadasi, "Land use change, urbanization, and change in landscape pattern in a metropolitan area," Science of the Total Environment, vol. 655, pp. 707-719, 2019.
[3] H. Yin, D. Pflugmacher, A. Li, Z. Li, and P. Hostert, "Land use and land cover change in Inner Mongolia - understanding the effects of China's re-vegetation programs," Remote Sensing of Environment, vol. 204, pp. 918-930, 2018.

[4] M. Pepe, L. Fregonese, and M. Scaioni, "Planning airborne photogrammetry and remote-sensing missions with modern platforms and sensors," European Journal of Remote Sensing, vol. 51, no. 1, pp. 412-436, 2018.

[5] Y. Lang, W. Song, and Y. Zhang, "Responses of the water-yield ecosystem service to climate and land use change in Sancha River Basin, China," Physics and Chemistry of the Earth, Parts $A / B / C$, vol. 101, pp. 102-111, 2017.

[6] S. Tiwari, C. Singh, S. Boudh, P. K. Rai, V. K. Gupta, and J. S. Singh, "Land use change: a key ecological disturbance declines soil microbial biomass in dry tropical uplands," Journal of Environmental Management, vol. 242, pp. 1-10, 2019.

[7] H. Long and Y. Qu, "Land use transitions and land management: a mutual feedback perspective," Land Use Policy, vol. 74, pp. 111-120, 2018.

[8] W. H. Maes and K. Steppe, "Perspectives for remote sensing with unmanned aerial vehicles in precision agriculture," Trends in Plant Science, vol. 24, no. 2, pp. 152-164, 2019.

[9] P. Singh, N. Kikon, and P. Verma, "Impact of land use change and urbanization on urban heat island in Lucknow city, Central India. A remote sensing based estimate," Sustainable Cities and Society, vol. 32, pp. 100-114, 2017.

[10] C. Hyandye and L. W. Martz, "A Markovian and cellular automata land-use change predictive model of the Usangu Catchment," International Journal of Remote Sensing, vol. 38, no. 1, pp. 64-81, 2017.

[11] Y. Bai, T. O. Ochuodho, and J. Yang, "Impact of land use and climate change on water-related ecosystem services in Kentucky, USA," Ecological Indicators, vol. 102, pp. 51-64, 2019.

[12] X. Lu, X. Zheng, and Y. Yuan, "Remote sensing scene classification by unsupervised representation learning," IEEE Transactions on Geoscience and Remote Sensing, vol. 55, no. 9, pp. 5148-5157, 2017.

[13] A. D. Barnes, K. Allen, H. Kreft et al., "Direct and cascading impacts of tropical land-use change on multi-trophic biodiversity," Nature ecology \& evolution, vol. 1, no. 10, pp. 1511-1519, 2017.

[14] J. Wang, Y. Lin, T. Zhai et al., "The role of human activity in decreasing ecologically sound land use in China," Land Degradation \& Development, vol. 29, no. 3, pp. 446-460, 2018.

[15] A. M. Hersperger, E. Oliveira, S. Pagliarin et al., "Urban landuse change: the role of strategic spatial planning," Global Environmental Change, vol. 51, pp. 32-42, 2018.

[16] R. Näsi, E. Honkavaara, M. Blomqvist et al., "Remote sensing of bark beetle damage in urban forests at individual tree level using a novel hyperspectral camera from UAV and aircraft," Urban Forestry \& Urban Greening, vol. 30, pp. 72-83, 2018.

[17] J. He, J. Huang, and C. Li, "The evaluation for the impact of land use change on habitat quality: a joint contribution of cellular automata scenario simulation and habitat quality assessment model," Ecological Modelling, vol. 366, pp. 5867, 2017.

[18] X. Wang, X. Dong, H. Liu et al., "Linking land use change, ecosystem services and human well-being: a case study of the Manas River Basin of Xinjiang, China," Ecosystem Services, vol. 27, pp. 113-123, 2017. 
[19] P. Fierro, C. Bertrán, J. Tapia et al., "Effects of local land-use on riparian vegetation, water quality, and the functional organization of macroinvertebrate assemblages," Science of the Total Environment, vol. 609, pp. 724-734, 2017.

[20] S. Khanal, J. Fulton, and S. Shearer, "An overview of current and potential applications of thermal remote sensing in precision agriculture," Computers and Electronics in Agriculture, vol. 139, pp. 22-32, 2017.

[21] R. P. Leitão, J. Zuanon, D. Mouillot et al., "Disentangling the pathways of land use impacts on the functional structure of fish assemblages in Amazon streams," Ecography, vol. 41, no. 1, pp. 219-232, 2018.

[22] M. Piquer-Rodríguez, V. Butsic, P. Gärtner et al., "Drivers of agricultural land-use change in the Argentine Pampas and Chaco regions," Applied Geography, vol. 91, pp. 111-122, 2018.

[23] G. Li, F. Zhang, Y. Jing, Y. Liu, and G. Sun, "Response of evapotranspiration to changes in land use and land cover and climate in China during 2001-2013," Science of the Total Environment, vol. 596-597, pp. 256-265, 2017.

[24] W. Liu, J. Zhan, F. Zhao, H. Yan, F. Zhang, and X. Wei, "Impacts of urbanization-induced land-use changes on ecosystem services: a case study of the Pearl River Delta Metropolitan Region, China," Ecological Indicators, vol. 98, pp. 228-238, 2019.

[25] A. S. Lafuite, G. Denise, and M. Loreau, "Sustainable land-use management under biodiversity lag effects," Ecological Economics, vol. 154, pp. 272-281, 2018. 